\title{
DIAGNOSTICS AND ASSESSMENT OF INTERCULTURAL COMMUNICATIVE COMPETENCE
}

\author{
Kassymbekova Markhabat \\ PhD candidate, Kazakh Ablai Khan University of International Relations and World Languages, \\ Kazakhstan, E-mail: marhabat.k@mail.ru
}

\begin{abstract}
The shift from the knowledge - based to the competence - based educational model became one of the urgent issues in educational systems worldwide. As the intercultural communicative competence (ICC) is considered as one of the main goals in foreign language acquisition, the learning process should also embody intercultural learning. Therefore it is important for the teacher to track his $\backslash$ her students' progress in becoming interculturally competent: how effective and appropriate they can communicate. The aim of this paper is to present a brief overview of research on diagnostics and assessment of intercultural communicative competence.
\end{abstract}

Keywords: competency-based approach, competence diagnostics, intercultural communicative competence (ICC), knowledge-based approach, learning outcomes

\section{INTRODUCTION}

The changes in political, economic and cultural spheres of life in the Republic of Kazakhstan after gaining the independence in 1991 raised the status of foreign languages and English in particular. Since the real contacts with foreigners were scarce in the country in the past, students learnt language(s) mostly for artificial use in the classroom. Nowadays Kazakhstan as an independent state has expanded its ties with other countries and the newly created socio-economic environment requires the revision of the educational system, development of the new efficient forms, methods and facilities of education that is a comprehensive theoretical and conceptual shift in language teaching.

As it has been mentioned above the newly created socio- cultural and political environment required shifting from passive to active language learning, when students will be able to use the acquired linguistic knowledge in real life situations. Therefore, competency -based approach as an outcome-based instruction would meet the new requirements of the current situation, as it gives transparent measurable description of the knowledge, skills, abilities and competences that students should possess at the end of a course. The new goal in foreign language education is considered as the formation of intercultural communicative competence that implies the ability to interact appropriately and effectively with representatives of the target culture.

Thus diagnosing and measuring of ICC formation in order to make the foreign language educational process more effective has become one of the essential questions under discussion. 


\section{KNOWLEDGE-BASED APPROACH VERSUS COMPETENCY -BASED APPROACH}

Together with allied fields such as psychology, pedagogy, discourse studies, cognitive linguistics and others the theories of Foreign Language Education (FLE) have been developed over the years. In contrast to the passive teaching methods in the past, which were mostly teacher centered, new pedagogical methods, based on these modern theories, require student engagement i.e. they are student -centered. In teacher centered classroom teacher decides on objectives, procedure, and content of education, whereas the student only listens and takes notes. The student centered classroom changes both teachers' and students' roles, making them two collaborating subjects of educational process. In such classroom learning is an active process in which students develop new ideas or concepts based on their knowledge, they select and transform information, construct hypotheses, and make decisions. In such classroom environments students display higher order thinking and problem solving skills, demonstrate metacognitive development, selfmonitoring of their learning and thinking. Zirbel (2007) emphasizes that “... students entering classrooms are neither 'blank slates' nor 'empty vessels' that can be filled with information. Plenty of educational research has shown that students actively think about their surroundings and try to make sense of them to some degree" (p.12).

Knowledge-based educational model in FLE, which was mainly applied in the Republic in the past, focused on language acquisition with its focus on only language forms that is, the correct pronunciation, grammar, and vocabulary acquisition and so on. But recent socio-economic changes have revealed that knowledge of a foreign language (language forms) is not enough for effective communication. The contradiction when students possess language forms well but nevertheless are not able to communicate effectively indicates a need for research into new relevant approaches.

In today's ever changing global world in order to meet unique demands of the 21 st century it is necessary to prepare next generation for success in an interconnected world. In other words, it is imperative to equip young generation with the skills that would enable them to successfully navigate in a global world. Therefore, the shift from knowledge based to competence based educational model became one of the urgent issues in educational system worldwide including Kazakhstan.

In the light of recent studies in the field of cognitive linguistics, socio linguistics, and discourse studies the development of personality is put forward. Bruner (1966) emphasizing the importance of being able to apply the knowledge in real situations states:

We teach a subject not to produce little living libraries on that subject, but rather to get a student to think mathematically for himself, to consider matters as a historian does, to take part in the process of knowledgegetting. Knowing is a process not a product (p.72).

As Kunanbayeva (2010) suggests this change from knowledge-based educational model to competency based model may be viewed as a change in paradigm of education (p. 69). Kuhn (1962) asserting that a change of paradigm is a sort of scientific revolution states "more clearly than most other episodes in the history of at least the physical sciences, these display what all scientific revolutions are about. Each of them necessitated the community's rejection of one time-honored scientific theory in favor of another incompatible with it". (p. 6)

\section{VARIOUS CONCEPTUALIZATIONS OF THE TERM COMPETENCE}

Before dwelling on how to develop and diagnose students' certain competences and ICC in particular, it is relevant to discuss various interpretations of the term competence in different educational contexts. The term competence in its wide definition refers to a combination of theoretical and practical knowledge and cognitive skills that enable a person to act effectively in a job or situation. However, even though a competence is not a new term the scholars have not come to consensus on the definition of this term. Different scholars use various definitions of the notion competence. In 2013, at Cross Border Seminar titled "Methods, Techniques and Tools to Diagnose Competences" in Warsaw, representatives of different countries presented the ways in which competency is defined in their countries, ways of classification of competences and existing competence diagnostic and assessment methods.

In Austrian context there are two definitions which "are considered to be particularly significant in discussions"(p. 10). First the definition of competence given by Weinert(2013) who "describes competencies as the cognitive abilities and skills individuals possess or learn in order to solve certain problems, and the associated motivational, volitional and social readiness and ability to use these solutions successfully and responsibly in various situations" (Zurcher, Reinhard, 2010, pp. 4-3). And there is another definition from Erpenbeck which highlights the competence "as a proneness to self-organized action" (as cited in Mosberger, Brigitte; Kasper, Ruth, 2009, p. 7). 
In German context the competence is viewed as a latent capacity of a person to perform a particular task and it is understood as the actual performance of this task.

In Slovakia competence is officially defined by the Act on Education as "... a demonstrated ability to use knowledge, skills, attitudes, value orientation and other capabilities to perform and implement functions according to given standards in work, while studying in personal and professional development of the individual and for his/her active involvement in society, in the future working and non-working life and in his/her further education"(Methods, techniques and tools to diagnose competences, May p.116).

In Kazakhstan competence also has been defined in diverse ways. Kunanbayeva (2010) summarizes definitions of competence given by Kazakhstan and Russian scholars and defines competence as "an acmeological category and denotes the potential for intellectual and professional development" (p. 105).

To sum up the above given definitions competence can be considered as a potential(latent) ability(capacity, proneness) to solve certain problems $\backslash$ perform a particular task and as well as for intellectual and professional development in future.

\section{INTERCULTURAL COMMUNICATIVE COMPETENCE ASSESSMENT AND DIAGNOSTICS STANDARDS}

The term communicative competence was initially coined by Hymes as a response to Noam Chomsky's concept linguistic competence. According to Hymes communicative competence is defined as speaker's internalized knowledge both of the grammatical rules of a language and of the rules for appropriate use in social contexts.

It is assumed that communicative competence can be formed when a child learns to speak his mother tongue. Though there are scholars who consider native speakership as a linguistic myth, and who "argue that its true meaning is no more or less than a proficient user of a language" (Alptekin, p.60). However, in foreign language acquisition as Alptekin (2002) states

"learners are not only expected to acquire accurate forms of the target language, but also to learn how to use these forms in given social situations in the target language setting to convey appropriate, coherent, and strategically effective meanings for the native speaker. Thus, learning a foreign language becomes a kind of enculturation, where one acquires new cultural frames of reference and a new world view, reflecting those of the target language culture and its speakers"(p. 58).

Thus not only knowledge of the grammar and vocabulary of a language but also the ability to use the language in socially and culturally appropriate ways is required in the contemporary world, to prepare the learners for successful interaction with people of other cultures. So in the Kazakhstani context the learning outcome in foreign language education is viewed as the formation of intercultural-communicative competence.

Concerning the quality in the field of higher education Green (1994) proposes five different approaches:

in terms of the exceptional (highest standards);

in terms of conformity to standards;

as fitness for purpose;

as effectiveness in achieving institutional goals; and

as meeting customers' stated or implied needs.

Analyzing all these five approaches it seems that all of them concern with competency. In other words, each of these approaches aims at achieving a certain competence. For example, in terms of conformity to the Common European Framework of Reference standards for languages, which has become an international benchmark for language ability, highlights the intercultural communicative competence as one of the main goals of foreign language teaching/learning.

Effectiveness in achieving institutional goals is considered as a well-defined set of competencies. Meeting customers' needs means providing educational services to students and supplying the job marketplace with competent and qualified specialists. Mangan (1992) states "As a business, an educational institution must be concerned about the effectiveness of its programs and the quality of its products and services."(pp. A25-26)

Fulks and Pacheco (2008) assume that:

Student learning outcomes (SLOs) are the specific observable or measurable results that are expected 
subsequent to a learning experience. These outcomes may involve knowledge (cognitive), skills (behavioral), or attitudes (affective) that provide evidence that learning has occurred as a result of a specified course, program activity, or process. An SLO refers to an overarching outcome for a course, program, degree or certificate, or student services area (such as the library). SLOs describe a student's ability to synthesize many discreet skills using higher level thinking skills and to produce something that asks them to apply what they've learned. SLOs usually encompass a gathering together of smaller discrete objectives through analysis, evaluation and synthesis into more sophisticated skills and abilities.(p.2)

There were done some researches (Corbaz, 2001; Moloney, 2008; Morgan, 2009; Crozet and Liddicoat, 1999) on evaluation of intercultural communicative competence in foreign language learners which highlight what students were supposed to demonstrate as their learning outcomes.

As the research shows different countries have been employing different competency assessment standards. In Austrian educational system educational counsellors have developed scientifically based standardized tests which are aimed at diagnosing skills, personal gifts and abilities through performance, interest and personality assessments. Also in Austria some guidance institutions have improved formats for competence diagnosis as following: skills audit, competence profile, skill counselling, ability portfolio, etc.

In Germany the scholars have developed cognitive knowledge tests, which are aimed at diagnosing knowledge (declarative and procedural) and performance. There is a huge variety of computer-based tests, in which work processes are simulated and standardized. These tests include presentations, role plays and psychological interviews using situational judgement and critical incident items.

In Hungary questionnaires, self-assessment tools, tests, checklists and group-session methods (workshop methods) are used to measure competences and career management skills.

Psychological diagnostic tests are usually allowed to be compiled and administered only by psychologists; it is probably due to the fact that they involve certain qualimetric 1 calculations. For example, in the Czech Republic only people with specific training and education are able to administer standardized psychodiagnostic methods and tools. Though qualimetric methods (developed on the basis of mathematical theories) are considered to be objective assessment tools (Subetto \& Selezneva, 1999; Sviridov, 1981), there are still not enough researches in the field of qualimetry of professional and personal development of specialists because of their complicated nature.

Alongside with psycho-diagnostic methods and tools of competence diagnostics also various tests, interviews, questionnaires and Situational Judgment Tests are being applied.

Different ways to assess or diagnose ICC have been developed over the years, such as "Intercultural Sensitivity Inventory" with 46 questions by Bhawuk \& Brislin(1992), "The Stages of Development" by Bennett (1993), that is based on two dimensions ethnocentrism and methnorelativism and many others. However they do not assess or diagnose the appropriacy of the language usage, they imply basically people's relations in intercultural encounters. Therefore there is a need to develop ways to assess or diagnose ICC in FL classrooms that can inform teachers about their students' intercultural performance. As Skopinskaja concludes "When assessing ICC, the teacher invariably becomes an observer of the intercultural learning process rather than of its end product." (p. 143) Modern ICC diagnostics and assessment types like performance, portfolio and interview, help the teacher to spot possible deviations and correct them.

\section{CONCLUSION}

Educational system responses the changes taking place in the society. In the past the objectives of FL teaching were acquiring language forms for artificial use in the classrooms, i.e. knowledge -based approach was applied in teaching and learning foreign languages. The recent socio- economic changes had great effect on foreign language teaching and learning in Kazakhstan. As an independent state the country has established different socio-economic and cultural ties with other countries. Therefore, the objectives of FLT needed revision, not only knowledge of language forms yet how to use those forms in real life situations. In this context the choice of competency-based approach and ICC as an outcome in FLE seems to meet the demands of the time.

The aim of foreign language education to develop students' ICC determines the importance of diagnostics and assessment of ICC. Diagnostics and assessment help highlight the students' progress in the process of intercultural learning.

\footnotetext{
${ }^{1}$ Qualimetry is a scientific discipline which concerns itself with the methods and problems of quantification of the quality of any object: things or processes, whether natural or man-made, products of labor or nature, whether living or inanimate, etc.()
} 


\section{REFERENCE LIST}

Alptekin, C., (2002). Towards intercultural communicative competence in ELT. ELT Journal, 56(1), 57-64.

Baker, C., (2006). Foundations of bilingual education and bilingualism (4th Ed.). Clevedon, England: Multilingual Matters.

Bruner Jerome S., (19660. Toward a theory of instruction, Cambridge, Mass.: Belknap Press of Harvard University.

Eric Witty, Barbara Gaston (Competency based assessment) Documento en líneadisponible en: retrieved from http://elearning.etito.co.nz/ Fecha de consulta: 01-10-14, March 9, 2015

Fantini, Alvino And Tirmizi, Aqeel, (20006. Exploring and Assessing Intercultural Competence, World Learning Publications. Paper 1.

http://digitalcollections.sit.edu/worldlearning_publications/1

Green, D. (1994). What is quality in higher education? Buckingham: SRHE; Open University Press.

Kuhn, Thomas, (1962). The Structure of Scientific Revolutions. Chicago: The University of Chicago Press. p. 3. ISBN 9780226458113.

Kunanbaeva S.S. (2010). Theory and practice of modern foreign language education. Almaty

Methods, techniques and tools to diagnose competences, Cross Border Seminar Warsaw, 14 - 15 May 2013, National Centre For Supporting Vocational And Continuing Education

Qualifications: Bologna Working Group on Qualifications Frameworks: A Framework for Qualifications of the European Higher Education Area, published by the Ministry of Science, Technology and Innovation, Copenhagen, February 2005. [online][Accessed 01 March 2015].

Availabe at: htpp//: www.bolognabergen2005.no/Docs/00Main_doc/050218_QF_EHEA.pdf (3.5.2006)

Roberts, C., Byram, M., BARRO, A., JORDAN, S.,(20010. Language Learners as Ethnographers. Clevedon, England: Multilingual Matters Ltd.

Skopinskaja, L. (2009). Assessing intercultural communicative competence: test construction issues. Synergies - Pays Riverains de la Baltique, 6, 135-144.

Shepard, L.A. (2000). The role of assessment in a learning culture. Educational Researcher, 29(7), 4-14.

Zirbel, E. L., (2007). Teaching to promote deep understanding and instigate conceptual change. Bulletin of the American Astronomical Society, 38, 1220. 